\title{
Plasminogen activator urokinase expression reveals TRAIL responsiveness and supports fractional survival of cancer cells
}

\author{
V Pavet ${ }^{\star, 1}$, Y Shlyakhtina ${ }^{1}$, T He ${ }^{2}$, DG Ceschin ${ }^{1,4}$, P Kohonen ${ }^{2,5}$, M Perälä $^{2}$, O Kallioniemi ${ }^{3}$ and H Gronemeyer ${ }^{\star, 1}$
}

Tumor necrosis factor-related apoptosis-inducing ligand (TRAIL/TNFSF10/Apo2L) holds promise for cancer therapy as it induces apoptosis in a large variety of cancer cells while exerting negligible toxicity in normal ones. However, TRAIL can also induce proliferative and migratory signaling in cancer cells resistant to apoptosis induced by this cytokine. In that regard, the molecular mechanisms underlying the tumor selectivity of TRAIL and those balancing apoptosis versus survival remain largely elusive. We show here that high mRNA levels of PLAU, which encodes urokinase plasminogen activator (UPA), are characteristic of cancer cells with functional TRAIL signaling. Notably, decreasing UPA levels sensitized cancer cells to TRAIL, leading to markedly increased apoptosis. Mechanistic analyses revealed three molecular events taking place in uPA-depleted cells: reduced basal ERK1/2 prosurvival signaling, decreased preligand decoy receptor 2 (DcR2)-death receptor 5 (DR5) interaction and attenuated recruitment of DcR2 to the death-inducing signaling complex upon TRAIL challenge. These phenomena were accompanied by increased FADD and procaspase-8 recruitment and processing, thus guiding cells toward a caspase-dependent cell death that is largely independent of the intrinsic apoptosis pathway. Collectively, our results unveil PLAU mRNA levels as marker for the identification of TRAIL-responsive tumor cells and highlight a key role of uPA signaling in 'apoptosis versus survival' decisionmaking processes upon TRAIL challenge.

Cell Death and Disease (2014) 5, e1043; doi:10.1038/cddis.2014.5; published online 30 January 2014

Subject Category: Cancer

Tumor necrosis factor-related apoptosis-inducing ligand (TRAIL/TNFSF10/Apo2L) is a member of the TNF family that induces apoptosis in a large variety of cancer cells while sparing normal ones. ${ }^{1}$ This cytokine binds as homotrimer to the extracellular domains of its plasma membrane-bound receptors inducing their oligomerization. Four TRAIL-specific receptors have been described, comprising two death receptors (DRs) that are able to trigger apoptosis (TNFRSF10A/TRAILR1/DR4, TNFRSF10B/TRAILR2/DR5) and two decoy receptors (DcRs) that bind the ligand but do not trigger apoptotic signaling (TNFRSF10C/TRAILR3/DcR1, TNFRSF10D/TRAILR4/DcR2). ${ }^{2-5}$ TRAIL binding to DR4 and DR5 induces the formation of the death-inducing signaling complex (DISC) owing to the recruitment of the specific adaptor protein FADD, which in turn engages initiator procaspase-8 and/or procaspase-10. DISC formation enables the autocatalytic cleavage and further activation of procaspases, thus triggering the death-executing cascade. ${ }^{6,7}$ Once an apoptosis-proficient DISC is formed, procaspases are activated to generate two possible scenarios: either the caspase cascade triggered by initiator caspases is sufficient to commit the cell to apoptosis (referred to as type I cells) or the additional activation of the intrinsic apoptosis pathway is required to induce cell death (type II cells). ${ }^{8}$ Notably, the final cell fate upon TRAIL challenge depends on multiple cellular factors including sequestration of the ligand by DcR1 and/or DcR2 at the cell surface, which can trigger survival signaling, ${ }^{9-11}$ the recruitment of the non-functional procaspase homolog $\mathrm{cFlip}^{12-14}$ and the relative levels of proteins that regulate the activation of the intrinsic mitochondrial pathway and/or modulate the activity of executor caspases. ${ }^{15,16}$

Importantly, it was also demonstrated that TRAIL induces proliferative, survival, migratory and inflammatory signals via activation of NF- $\kappa$ B, PI3K/Akt, MAPK and JNK. ${ }^{17}$ The existence of non-apoptotic TRAIL signaling was demonstrated for apoptosis-resistant cancer cells, primary childhood leukemia and non-tumorigenic scenarios such as rheumatoid arthritis. $^{17-20}$ Therefore, depending on their response to

\footnotetext{
${ }^{1}$ Institut de Génétique et de Biologie Moléculaire et Cellulaire, CNRS/INSERM/UdS/CERBM, BP10142, 67404 Illkirch Graffenstaden, France; ${ }^{2}$ Medical Biotechnology, VTT Technical Research Centre of Finland and University of Turku, Turku, Finland and ${ }^{3}$ FIMM-Institute for Molecular Medicine Finland, University of Helsinki, Helsinki, Finland

*Corresponding authors: H Gronemeyer or V Pavet, Institut de Génétique et de Biologie Moléculaire et Cellulaire, CNRS/INSERM/UdS/CERBM, BP10142, 1 Rue Laurent Fries, 67404 Illkirch-Strasbourg, Alsace, France. Tel: + 3338865 3473; Fax: + 3338865 3437; E-mail: hg@ igbmc.fr (HG) or Tel: + 33388653418 ; Fax: + 3338865 3437; E-mail: vpavet@igbmc.fr (VP)

${ }^{4}$ Current address: Faculty of Agrarian Sciences, National University of Comahue and National Scientific and Technical Research Council (CONICET), Cinco Saltos, Río Negro, Argentina

${ }^{5}$ Current address: Institute of Environmental Medicine, Division of Molecular Toxicology, Karolinska Institutet, Stockholm, Sweden

Keywords: Apo2L/TRAIL/TNFSF10; PLAU; uPA; apoptosis

Abbreviations: PLAU, plasminogen activator urokinase; UPA, urokinase plasminogen Activator; uPAR, urokinase plasminogen activator receptor; DISC, deathinducing signaling complex; TRAIL-R, TRAIL receptor

Received 24.8.13; revised 19.11.13; accepted 26.11.13; Edited by G Raschellá
} 
TRAIL, cancer cells can be grouped into three classes: (i) the entire population commits to apoptosis, (ii) is inherently resistant to cell death induced by TRAIL or (iii) only a part of the cell population dies, while a significant fraction survives the treatment and may even proliferate (referred to as 'fractional killing'). ${ }^{21}$ From the mechanistic point of view, it was shown that activation of survival pathways by TRAIL involves assembly of a secondary signaling complex that retains the DISC components FADD and caspase-8, and recruits RIP1, TRAF2, TRADD and NEMO/IKK. ${ }^{22}$ However, contrary to the well-known cellular mechanisms mediating TRAIL-induced cell death, the understanding of how TRAIL and TRAIL receptors induce the formation of this secondary complex and the triggering of non-apoptotic cascades is still in its infancy.

Taken together, the numerous cellular factors modulating the response to TRAIL and the dual nature of the signaling triggered by this cytokine may lead to the generation of resistant populations. In that regard, even though combining TRAIL-based approaches with multiple therapeutic agents improves the apoptotic response and diminishes the chances to generate resistance, ${ }^{23}$ only proteasome inhibitors were shown to revert acquired TRAIL resistance. ${ }^{24}$ Therefore, the identification of tumor features predicting the response of cancer cells to TRAIL, the understanding of the mechanisms orchestrating the outcome and the characterization of molecular targets that will improve the initial apoptotic response are important goals to achieve.

By comparative transcriptome profiling of stepwise tumorigenesis systems, ${ }^{25,26}$ we observed that PLAU mRNA levels increase in tumorigenesis models and primary human tumors relative to normal tissue and correlate with sensitivity to TRAIL-induced cell death. We demonstrate that diminishing urokinase plasminogen activator (UPA) levels leads to decreased ERK1/2 survival signaling, thus lowering the cellular threshold to trigger TRAIL-induced apoptosis. Importantly, we show that UPA depletion alters the DISC composition by reducing the preligand and TRAIL-induced DcR2-DR5 interaction. Collectively, these molecular events lead to the formation of an apoptosis-proficient DISC, resulting in pronounced caspase-dependent apoptosis and preventing the generation of resistant populations. All in all, our work unveils an intricate cross-talk between UPA and TRAIL signaling, which highlights the use of PLAUmRNA as a marker of response and as a potential target for improving the apoptogenic action of TRAIL.

\section{Results}

Stepwise human tumorigenesis systems as cellular model to study TRAIL-induced signaling. Although the natural process of carcinogenesis is highly complex and specific to each cell type and/or carcinogenic insult, in vitro models recapitulate the basic events necessary for cellular transformation. ${ }^{25,26}$ In these models, normal primary human cells are transformed in a stepwise manner by the introduction of the catalytic subunit of telomerase ( $h T E R T)$, the early region of the SV40 virus (SV40 ER) and the activated allele of $H$-ras (H-rasV12) (Figure 1a). These cellular systems display several hallmarks of tumorigenesis ${ }^{27}$ and allow comparing cancer cells with their normal progenitors, which is difficult to achieve with cancer cell lines derived from primary human tumors. We observed that normal cells from epithelial and mesenchymal origins (human embryonic kidney (HEK), foreskin fibroblasts (BJ), respectively) are resistant to TRAIL-induced cell death, whereas sensitivity to apoptosis is acquired along the transformation process, with transformed cells displaying the major apoptotic rate (Figure 1b). Therefore, in line with previous reports, ${ }^{28-31}$ our data indicate that stepwise tumorigenesis systems recapitulate the tumor selectivity reported for TRAIL. Interestingly, we observed that transformed cells from stepwise models display fractional killing even when exposed to high doses of TRAIL (>60-fold above the $\mathrm{IC}_{50}$; Figures $1 \mathrm{~b}$ and $\mathrm{c}$ (population 1) and Supplementary Figures 1a and b). Furthermore, cells surviving the first challenge remained resistant to further TRAIL treatments (Figure 1c, populations 2 and 3) and continued to proliferate in the presence of the cytokine (Figure 1d and Supplementary Figure 1c). Notably, when TRAIL treatment was discontinued, the resistant cell population reverted to the initial apoptotic rate (Figure 1c, population 4). The reversible nature of resistance suggests that it is not based on the selection of inherently resistant clones within the initial population, and that its establishment and maintenance is TRAIL-dependent. Taken together, these results indicate that stepwise models are valuable cell systems for the identification of genes whose altered expression is characteristic of tumor cells, and whose products may modulate apoptosis versus survival signaling triggered by this cytokine.

PLAU mRNA levels correlate with TRAIL-induced apoptosis in cancer cells. To identify genes overexpressed in cancer cells relative to normal ones and whose encoded proteins may modulate the response to TRAIL, we compared the transcriptomes of normal, immortalized and transformed cells from stepwise models (HEK versus HA1ER; BJ versus BJELR; HA1E versus HA1ER; BJEL versus BJELR). Genes with increased expression in transformed cells relative to normal and immortalized ones were selected (fold change $>2.5 ; P$-value $<0.01)$. From 316 genes that showed higher expression in HA1ER than in HEK cells, 39 also displayed a significant upregulation from the immortalization to transformation step (HA1ER versus HA1E; Figure 2a and Supplementary Figure 2a). A similar analysis of the BJ model revealed a set of 20 genes with such characteristics (Figure 2a and Supplementary Figure 2b). A comparison of the two systems identified four genes showing high expression levels in transformed cells from both stepwise models (Figure 2a). Among those, only PLAU mRNA was significantly increased in a panel of primary human tumors from different tissue origins as compared with normal tissue (Figure 2b; IST database, see Materials and Methods). In line with this, in silico analysis revealed that PLAU mRNA was significantly increased in breast cancer as compared with normal breast tissue, particularly in tumors showing a Her2 +, PgR - and/or p53 mutant phenotype (Figure 2b and Supplementary Figure 2c). Moreover, we observed that higher levels of PLAU mRNA correlate with a reduced relapse-free survival in breast cancer patients (Figure 2c), as previously reported for its encoded protein UPA. ${ }^{32,33}$ 
a
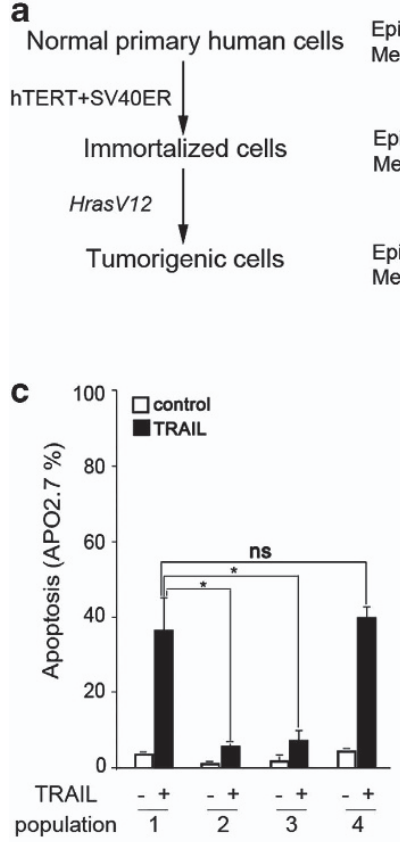

Epithelial: HEK Mesenchymal: BJ

Epithelial: HA1E Mesenchymal: BJEL

Epithelial: HA1ER Mesenchymal: BJELR
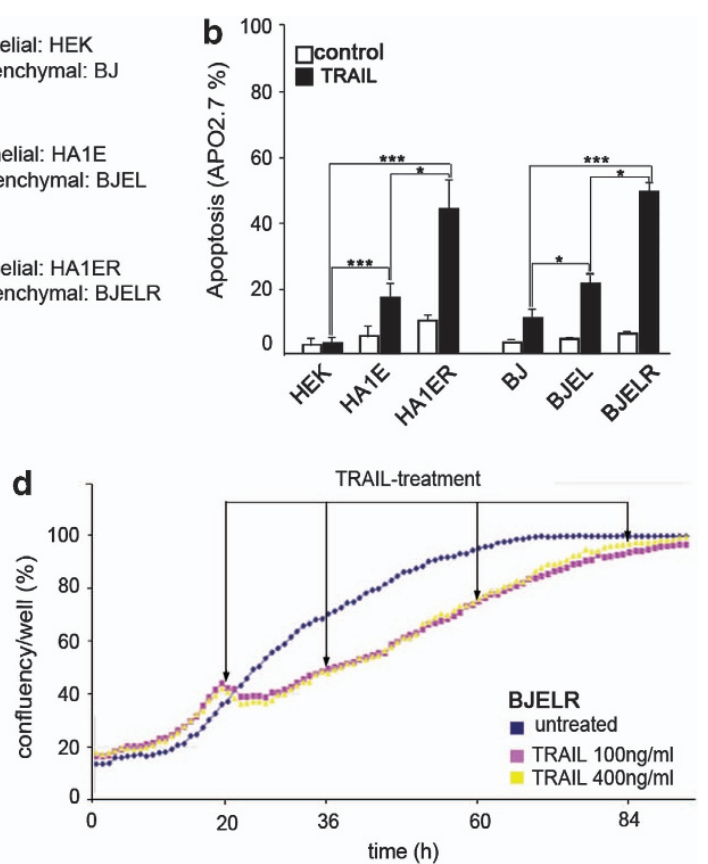

Figure 1 RAS-derived stepwise tumorigenesis models recapitulate TRAIL-tumor-selective apoptosis and display fractional killing and proliferation upon treatment. (a) Scheme representing RAS-derived stepwise tumorigenesis models generated from human foreskin fibroblast (BJ) and human embryonic kidney cells (HEK). Genetic elements introduced for stepwise transformation are indicated. (b) Apoptosis observed in populations of normal, immortalized and RAS-transformed cells derived from HEK and BJ stepwise tumorigenesis models. Basal cell death in untreated populations (control; white bars) and cell death after $16 \mathrm{~h}$ of treatment with $1 \mu \mathrm{g} / \mathrm{ml}$ of TRAIL (TRAIL; black bars) is displayed. Apoptosis was analyzed by flow cytometry as the percentage of APO 2.7-positive cells. Histograms represent the mean \pm S.D. from at least three independent biological replicates. (c) Apoptosis was analyzed as in (b) after $16 \mathrm{~h}$ of treatment with $1 \mu \mathrm{g} / \mathrm{ml}$ TRAIL in populations of BJELR-naive cells (population 1), resistant cells obtained from 24 (population 2) or 48 (population 3) hours of pre-exposure to TRAIL ( $500 \mathrm{ng} / \mathrm{ml}$ ) and revertant cells (population 4) obtained from a pretreatment of BJELR cells with TRAIL $(500 \mathrm{ng} / \mathrm{ml})$ during $48 \mathrm{~h}$, followed by a release from exposure to the cytokine during 12 days before receiving a new dose of $1 \mu \mathrm{g} / \mathrm{ml}$ TRAlL during $16 \mathrm{~h}$. Histograms represent the mean \pm S.D. from two independent biological replicates, representative of at least three independent experiments. Statistical significance in (b and $\mathbf{c}$ ) was calculated by applying two-tailed, unpaired Student's $t$-test, ${ }^{* \star} P$-value $<0.0005$, ${ }^{*} P$-value $<0.05$. (d) Proliferation of BJELR cells upon sequential treatment with TRAIL. Cells were plated and allowed to proliferate during $20 \mathrm{~h}$ before receiving a first dose of TRAIL ( $100 \mathrm{or} 400 \mathrm{ng} / \mathrm{ml}$, as indicated), were maintained under continuous exposure to the cytokine and further received sequential treatments at the indicated time points (arrows). Untreated cells were grown in parallel as proliferation controls. Images were acquired every hour using INCUCYTE and confluency was evaluated as the percentage of the surface covered by cells. The mean value obtained from two independent wells per time point is displayed and is representative of four independent biological replicates

Importantly, previous studies have revealed a correlation between high uPA levels and poor response of human tumors to standard cancer therapies. ${ }^{34-36}$ To elucidate a potential link between PLAU expression and response to TRAIL, these two features were first correlated in a study of 11 breast and prostate cancer cell lines. Interestingly, a direct correlation between PLAU mRNA levels and TRAIL-induced apoptosis was observed (Figure 2d). A similar analysis was performed with a publically available transcriptome data set of 20 breast cancer cell lines. ${ }^{37}$ These cell lines were classified into two groups according to their apoptotic response toward TRAIL (death rate higher or lower than 50\%) and PLAU mRNA levels for each group were assessed from the transcriptome data sets (Figure 2e). As observed in our initial study (Figure 2d), cell lines triggering prominent apoptosis presented higher levels of PLAU mRNA (Figure 2e). Taken together, these data demonstrate that high PLAU mRNA levels are indicative for cancer cells that exhibit a functional TRAIL apoptotic signaling cascade, independently of their genetic background, tissue origin and the transformation events that led to the malignancy.

PLAU and PLAUR expression support cell survival upon TRAIL challenge. A positive correlation between PLAU expression and TRAIL-induced apoptosis does not a priori imply that UPA supports the apoptogenic response to TRAIL. Indeed, UPA and its membrane-bound receptor urokinase plasminogen activator receptor (UPAR) have been primarily documented as promoting the proliferation and survival of cancer cells; ${ }^{38-40}$ however, other reports propose that UPA/UPAR may support cell death. ${ }^{41-43}$ Notably, the previously analyzed cancer cell lines and stepwise transformed cells with high expression of PLAU mRNA show fractional killing (Figures $1 \mathrm{~b}, \mathrm{~d}$ and $2 \mathrm{~d}$ and Supplementary Figure 1). Therefore, we evaluated whether uPA was functionally involved in the response to TRAIL, either by supporting apoptosis or survival upon exposure to this cytokine. Interestingly, increased apoptosis was observed in BJELR cells upon depletion of UPA or its membranebound receptor uPAR (Figures $3 a$ and $b$ and Supplementary Figures $3 a$ and $b$ ). Comparable results were obtained when UPA or UPAR were depleted in HA1ER cells (Supplementary Figures $3 c-e)$. These data indicate that UPA and UPAR are factors that counterbalance TRAIL-induced apoptosis in $H$-rasV12 tumorigenic cells independently of their genetic background and highlight their functional relevance in the generation of resistant populations upon TRAIL challenge. 
a BJ BJEL BJELR HEK HA1E HA1ER

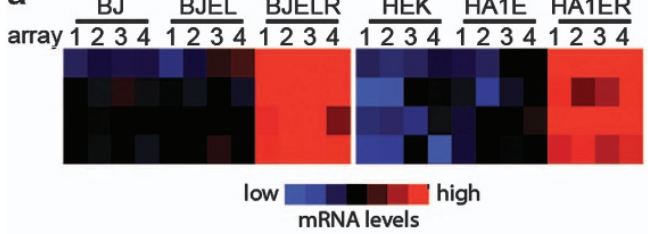

b
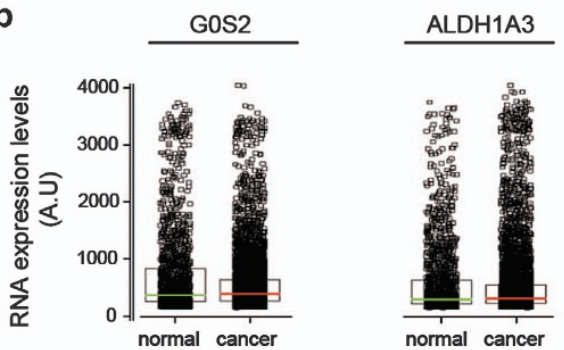

C

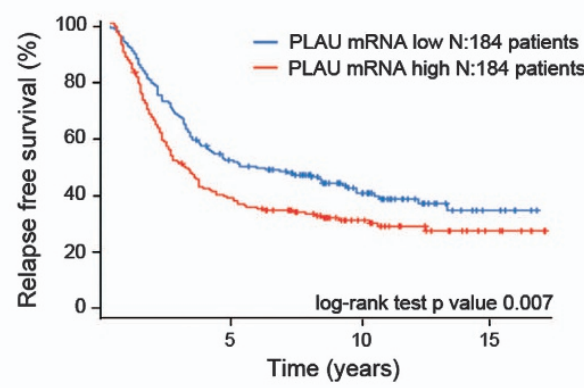

$\begin{array}{llcc}\text { Gene name } & \text { GeneBank } & \text { BJELR/BJ f.c. } & \text { HA1ER/HEK f.c. } \\ \text { IL1B } & \text { NM_000576 } & 32.92 & 35.67 \\ \text { PLAU } & \text { NM_002658 } & 4.84 & 5.23 \\ \text { G0S2 } & \text { NM_015714 } & 5.07 & 8.98 \\ \text { ALDH1A3 } & \text { NM_000693 } & 4.43 & 5.95\end{array}$

IL1B

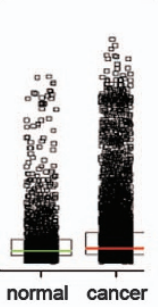

d

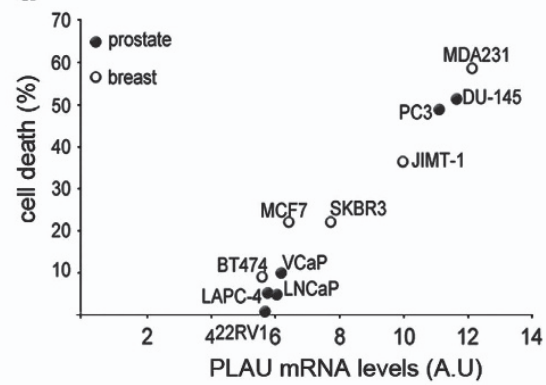

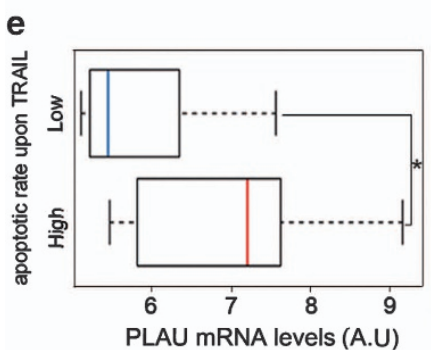

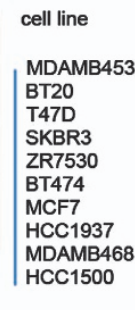

\begin{tabular}{cc|c}
$\begin{array}{c}\text { apoptotic } \\
\text { rate }\end{array}$ & $\begin{array}{c}\text { PLAU mRNA } \\
\text { (A.U) }\end{array}$ & cell line \\
low & 5.19 & \\
low & 5.22 & SUM149PT \\
low & 5.30 & MDAMB436 \\
low & 5.47 & HS578T \\
low & 5.48 & MD49 \\
low & 5.58 & HCC38 \\
low & 5.65 & MDAMB157 \\
low & 6.43 & SUM159PT \\
low & 6.80 & HCC1954 \\
low & 7.65 & AU565 \\
& &
\end{tabular}

$\begin{array}{cc}\begin{array}{c}\text { apoptotic } \\ \text { rate }\end{array} & \begin{array}{c}\text { PLAU mRNA } \\ \text { (A.U) }\end{array} \\ \text { high } & 9.25 \\ \text { high } & 8.13 \\ \text { high } & 7.71 \\ \text { high } & 7.55 \\ \text { high } & 7.50 \\ \text { high } & 7.08 \\ \text { high } & 6.50 \\ \text { high } & 5.90 \\ \text { high } & 5.65 \\ \text { high } & 5.55\end{array}$

Figure $2 P L A U$ mRNA level increases during neoplastic transformation and is a tumor feature whose expression correlates with the rate of apoptosis triggered in response to TRAIL. (a) Expression heatmaps corresponding to the four upregulated genes common between HEK and BJ RAS-derived stepwise models. IL1B: interleukin $1 \beta$; PLAU: plasminogen activator urokinase; G0S2: G0/G1 switch 2 and $A L D H 1 A 3$ : aldehyde dehydrogenase 1 family, member A3. Results from four independent transcriptome datasets ('array 1-4') are displayed. Mean fold change ('f.c.') differences in their expression between normal and transformed cells from each model are indicated. (b) G0S2, IL1B, ALDH1A3, and PLAU mRNA levels were analyzed for 1840 healthy and 6806 malignant human primary samples from different tissue origin using the GeneSapiens database (http: //www.genesapiens.org). Box plots displaying median and interquartile range (25-75\%) of mRNA levels in each data set are shown. For PLAU mRNA, expression in normal and malignant breast cancer samples is depicted. Statistical significance of the difference between groups was calculated with two-tailed unpaired Student's $t$-test. ${ }^{*} P$-value $<0.05$. (c) Relapse-free survival curve of breast cancer patients according to PLAU mRNA levels. Three hundred and sixty-eight patients were ranked according to the expression level of PLAUmRNA and divided into 184 PLAUmRNA high and 184 PLAUmRNA low patients. The percentage of patients with relapse-free survival is plotted along 15 years. Statistical significance between the two groups is shown as log-rank test, $P$-value $<0.007$. (d) TRAIL-induced cell death in breast and prostate human cancer cell lines was evaluated by CellTiter-Glo luminescence assay and levels of PLAU mRNA were extracted from Affymetrix GeneChip U133 Plus 2.0 array-based transcript profiling (see Materials and Methods). Correlation plot between cell death upon TRAIL treatment and PLAU mRNA levels is displayed (Pearson's correlation $r=0.82$, two-tailed $P$-value $<0.003$ ). The average of three technical replicates representative of three independent biological experiments is shown. (e) Correlation between $P L A U$ mRNA expression and the apoptotic response to TRAIL of a publically available data set of breast cancer cell lines. ${ }^{37}$ Twenty breast cancer cell lines were grouped according to whether they were reported to display an apoptotic rate higher ('High') or lower ('Low') than $50 \%$ upon TRAIL treatment. ${ }^{37}$ PLAU mRNA levels in each group were calculated from the transcriptome data set and are displayed as box plots of the median and interquartile range $(25-75 \%)$. ${ }^{*} P$-value $<0.05$. Cell lines classified as showing 'Low' and 'High' apoptotic rate upon TRAIL and the corresponding PLAU mRNA levels in arbitrary units ('AU') are specified on the right

uPA depletion lowers the cellular threshold for triggering caspase-dependent TRAIL-induced apoptosis. It is generally believed that low doses of TRAIL induce a poor apoptotic response and may generate resistance, whereas exposure to high levels of this cytokine results in extensive cell death, indicating the existence of a cellular threshold for triggering apoptosis (referred hereafter as 'sensitivity'). To evaluate whether uPA knockdown modifies sensitivity to TRAIL-induced cell death, uPA-depleted cells were exposed either to high doses of TRAIL during different time points 


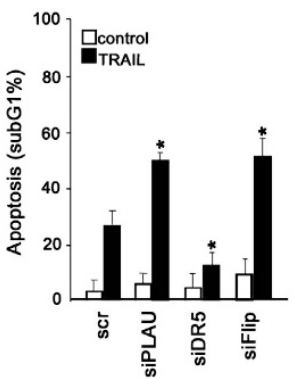

b 70

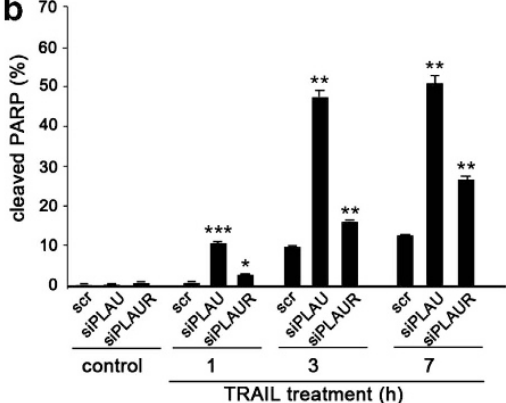

d

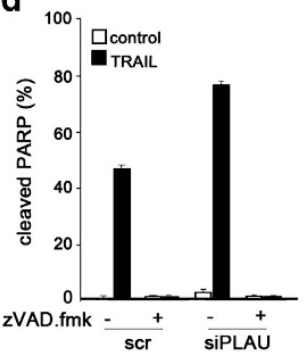

f
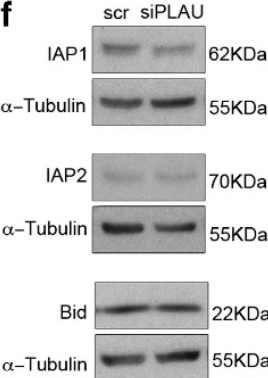

e

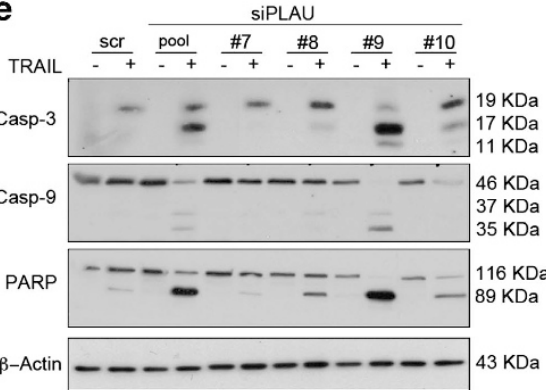

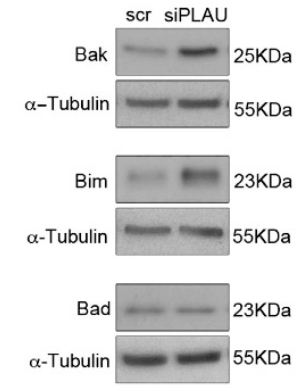
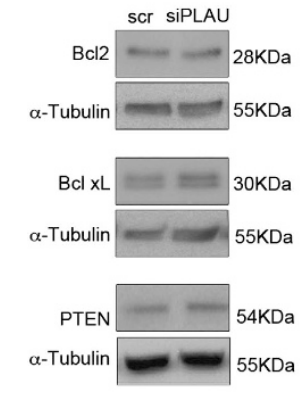

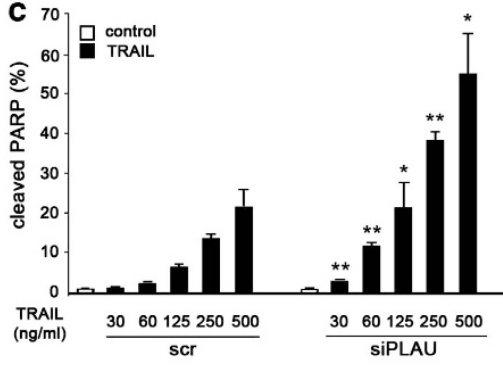

$g_{100}$
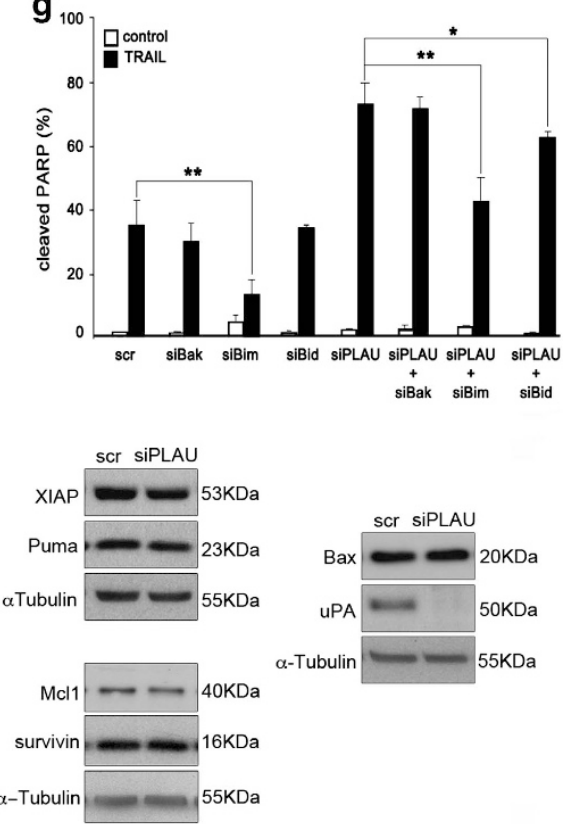

Figure 3 uPA expression is required for cell survival upon TRAIL treatment in RAS-derived stepwise tumorigenic cells. (a) Effect of uPA depletion on the response of BJELR cells to TRAIL. Cells were transfected with pooled siRNAs targeting PLAU mRNA ('siPLAU'), Death Receptor 5 mRNA ('siDR5'), cFlip mRNA ('siFlip') or non-targeting scramble siRNAs ('scr'). Forty-eight hours after transfection, cells were either left untreated as control of basal cell death or challenged with $1 \mu \mathrm{g} / \mathrm{ml}$ TRAlL during $16 \mathrm{~h}$. Flow cytometry analysis was performed to assess the percentage of cells displaying sub-G1 DNA. Results from at least two independent biological replicates are displayed as histograms (mean \pm S.D.). (b) Time course analyzing the effect of UPA or UPAR depletion on the apoptotic response of BJELR cells to TRAIL. Cells were transfected with pooled siRNAs targeting PLAU mRNA ('siPLAU'), PLAUR mRNA ('siPLAUR') or non-targeting scramble siRNAs ('scr'). Forty-eight hours after transfection, cells were either left untreated or challenged with $1 \mu \mathrm{g} / \mathrm{ml}$ TRAIL. Apoptosis was determined by flow cytometry as the percentage of cells displaying positive labeling for cleaved PARP at 1,3 and $7 \mathrm{~h}$ after treatment. Results from two independent biological replicates are displayed as histograms (mean \pm S.D.) and are representative of at least three independent experiments. Statistical significance between either knock down relative to scramble-transfected cells was calculated. (c) Effect of uPA depletion on the sensitivity threshold of BJELR cells to trigger TRAIL-induced apoptosis. BJELR cells were transfected with pooled siRNAs targeting PLAU mRNA ('siPLAU') or non-targeting scramble siRNAs ('scr'). Forty-eight hours after transfection, cells were either left untreated (white bars) or treated with increasing doses of TRAIL (30,60, 125, $250 \mathrm{or} 500 \mathrm{ng} / \mathrm{ml}$ TRAIL, black bars) during $3 \mathrm{~h}$. Apoptosis was analyzed by flow cytometry as the percentage of cells displaying positive labeling for cleaved PARP. Results obtained from two independent biological replicates are displayed as histograms (mean \pm S.D.). Statistical significance between uPA knockdown relative to scramble-transfected cells at the corresponding dose of TRAIL was calculated. (d) Caspase dependency of TRAIL-induced cell death in UPA knockdown cells. BJELR cells were transfected either with pooled siRNAs targeting PLAU mRNA ('siPLAU') or non-targeting scramble siRNAs ('scramble'), and $48 \mathrm{~h}$ after transfection, cells were either pretreated with $100 \mu \mathrm{M}$ zVAD.fmk caspase inhibitor or vehicle (dimethylsulfoxide (DMSO)) for $1 \mathrm{~h}$ and were either left unchallenged or treated with $1 \mu \mathrm{g} / \mathrm{ml}$ of TRAlL for $5 \mathrm{~h}$. Apoptosis was analyzed by flow cytometry as the percentage of cells displaying positive labeling for cleaved PARP. Results obtained from two independent biological replicates are displayed as histograms (mean \pm S.D.). (e) Generation of cleaved products of caspase-3, caspase-9 and PARP at early time points of the response to TRAIL. BJELR cells were transfected either with pooled siRNAs targeting PLAU mRNA ('siPLAU pool'), four individual siRNAs targeting different regions of the PLAU mRNA ('no. 7, no. 8, no. 9 and no. 10', see Supplementary Figure S4b) or non-targeting scramble siRNAs ('scr'). Forty-eight hours after transfection, cells were left untreated (' - ') or challenged with $1 \mu \mathrm{g} / \mathrm{ml}$ TRAIL ('+ ') during $45 \mathrm{~min}$ and total cell extracts were processed for western blot. Caspase-3 ('Casp-3'), caspase-9 ('Casp-9') and PARP cleavage were analyzed. $\beta$-Actin, loading control. (f) Cellular levels of pro- and antiapoptotic proteins reported to modulate TRAIL-induced apoptosis upon UPA knockdown. BJELR cells were transfected either with pooled siRNAs targeting PLAU mRNA ('siPLAU') or non-targeting siRNAs ('scr'), and $48 \mathrm{~h}$ after transfection, total cell extracts were processed for western blot analyzing the indicated pro- and antiapoptotic proteins. uPA level in control samples and upon knock down is shown. $\alpha$-Tubulin, loading control. (g) Requirement of the intrinsic mitochondrial pathway for triggering TRAlL-induced apoptosis in uPA-depleted cells (top panel). Cells were transfected with pooled siRNAs targeting PLAU mRNA ('siPLAU'), Bak mRNA ('siBak'), Bim mRNA ('siBim'), Bid mRNA ('siBid'), nontargeting scramble siRNAs ('scr') or double-transfected ('siPLAU + siBak', 'siPLAU + siBim' and 'siPLAU + siBid'). Forty-eight hours after transfection, cells were either left untreated or challenged with $1 \mu \mathrm{g} / \mathrm{ml}$ TRAIL during $7 \mathrm{~h}$. Apoptosis was determined by flow cytometry as the percentage of cells displaying positive labeling for cleaved PARP. Results obtained from two biological replicates are displayed as histograms (mean \pm S.D.) and are representative of a least three independent experiments. Statistical significance in (a, $\mathbf{b}, \mathbf{c}$ and $\mathbf{g}$ ) was calculated by applying two-tailed, unpaired Student's $t$-test, ${ }^{* \star \star} P$-value $<0.005$; ${ }^{* \star} P$-value $<0.005$; ${ }^{*} P$-value $<0.05$ 
(Figure 3b) or to increasing doses of the cytokine (Figure 3c), and the percentage of apoptotic cells was analyzed. UPA depletion resulted in a $\sim 4$-fold increase of sensitivity for triggering cell death upon TRAIL challenge, supporting the notion that diminishing uPA levels reduces the cellular threshold for triggering TRAIL-induced cell death (Figures $3 b$ and $c$ ).

Although it is widely accepted that apoptosis is the main type of cell death triggered through DRs of the TNF family, it was reported that TNF and TRAIL could trigger caspaseindependent necroptosis. ${ }^{44}$ To elucidate the molecular mechanisms underlying sensitization to TRAIL upon UPA knockdown, its dependence on caspase activity was analyzed. We observed that TRAIL-induced cell death was abolished in uPA knockdown and control samples in the presence of the pancaspase inhibitor zVAD.fmk (Figure 3d). Moreover, western blot assays revealed that UPA depletion promoted the generation of cleaved products of caspases-3, caspase- 9 and PARP at earlier time points of exposure to TRAIL as compared with controls (Figure $3 e$ and Supplementary Figure $4 a$ ). These results were obtained by using an siRNA pool as well as four individual siRNAs targeting different regions of PLAU mRNA (Figure $3 e$ and Supplementary Figure $4 b$ ), supporting that the increase in apoptosis was neither due to a synthetic nor to an individual off-target effect of these siRNA molecules. Taken together, our results demonstrate that the increased cell death observed upon uPA knockdown proceeds through the classical caspasedependent TRAIL-induced apoptosis cascade.

Enhanced sensitivity to TRAIL-induced apoptosis upon uPA knockdown could originate from an imbalance of proand/or antiapoptotic proteins regulating the response to TRAIL. Indeed, alterations in levels of Bcl-2 family members have been previously reported upon uPAR knockdown in cancer cells. ${ }^{38,45}$ In that regard, increased levels of proapoptotic Bim and Bak were observed, indicating that UPA knockdown changes the expression pattern of Bcl-2 family members to a proapoptotic setting (Figure 3f). Therefore, we investigated whether a cross-talk between the extrinsic and intrinsic apoptotic pathways was required for the sensitization effect observed upon uPA knockdown. By concomitantly decreasing the levels of either Bak, Bim, Bid and of PLAU, we showed that the enhanced sensitivity to TRAIL-induced apoptosis upon UPA depletion was significantly diminished by reducing Bim, whereas a decrease of Bak levels did not have any significant effect (Figure $3 g$ and Supplementary Figure 4c). Moreover, Bid-mediated activation of the intrinsic mitochondrial apoptotic cascade had only a mild effect on the sensitization observed upon uPA depletion, suggesting that other molecular mechanisms besides the activation of the intrinsic mitochondrial cascade underlie the sensitization to TRAIL in uPA-depleted cells. Previous reports described the involvement of MAPK, Akt and NF- $\kappa$ B signaling in cell survival upon TRAIL challenge. ${ }^{17}$ In this context, we observed that populations of BJELR cells surviving TRAIL treatment display increased levels of ERK1/2, Akt and $\mathrm{I}_{\kappa} \mathrm{B} \alpha$ phosphorylation as compared with those in the initial naive cell population (Figure 4a). Among these cascades, ERK1/2 and Akt were described as modulated by the UPA/UPAR system. ${ }^{39,46,47}$ Therefore, abnormal ERK1/2 and/or Akt phosphorylation could account for the enhanced apoptotic response to TRAIL in uPA-depleted cells. To substantiate this hypothesis, total and phosphorylated ERK1/2 and Akt were analyzed upon uPA knockdown and, whereas no differences in Akt phosphorylation were found, basal ERK1/2 phosphorylation decreased in the whole cell population (Figures $4 b$ and c). Importantly, blocking ERK1/2 phosphorylation in BJELR cells by using U0126 MEK1/2 inhibitor (Supplementary Figure 4d) enhanced their apoptotic response to TRAIL (Figure 4d). These data suggest that the ERK1/2 cascade supports cell survival upon exposure to TRAIL in this model; thus, decreased basal ERK1/2 signaling as a consequence of UPA depletion accounts - at least partially - for the enhanced sensitivity to TRAIL-induced cell death.

UPA depletion alters DcR2 recruitment to the DISC-promoting caspase-8 processing. uPA knockdown resulted in a higher number of cells displaying caspase-8 cleavage upon TRAIL treatment (Figure 5a), suggesting that levels of DISC components and/or DISC composition itself could be affected upon UPA depletion. In that regard, no changes in total protein levels of DR4, DR5, DcR1, cFlip, FADD or procaspase-8 were observed, whereas a mild decrease on total DcR2 was evidenced (Figure 5b, lane 1 versus 3 and Supplementary Figure 5a). However, no differences were detected when surface levels of DR4, DR5, DcR1 and DcR2 were analyzed by flow cytometry (Figure 5c). Therefore, we analyzed whether increased caspase-8 activation originated from changes of the DISC composition. For that, the DISC was immunoprecipitated by using anti-DR5 antibodies and the co-immunoprecipitation of cognate DISC members was revealed by western blot. We observed that DcR2 displayed preligand association to DR5 ${ }^{48}$ (Figure 5b, lane 5), which was further enhanced by exposure to the cytokine (Figure 5b, lane 6 versus 5), whereas DcR1 was not detected at the DISC (not shown). Moreover, recruitment of FADD, DR4 as well as recruitment and cleavage of procaspase-8 and cFlipL (but not FlipS) were entirely TRAIL-dependent (Figure 5b, lane 6 versus 5). Interestingly, uPA knockdown resulted in lower preligand association of DcR2 with DR5 (Figure 5b, lane 7 versus 5) and in a reduced recruitment of DcR2 to the DISC after TRAIL exposure (Figure $5 \mathrm{~b}$, lane 8 versus 6 ). The antiapoptotic role of DcR2 in stepwise models was confirmed by DcR2 knockdown followed by TRAIL challenge (Figures $5 \mathrm{~d}$ and $\mathrm{e}$ and Supplementary Figures $5 \mathrm{~b}$ and $\mathrm{c}$ ). Interestingly, neither UPA nor UPAR co-immunoprecipitated with DR5, suggesting that these molecules are not components of the DISC in our experimental conditions. Concomitant to the decrease of DcR2 recruitment upon uPA knockdown, enhanced FADD and caspase-8 recruitment and cleavage were observed (Figure 5b, lane 8 versus 6). Taken together, these results show that increased apoptotic response to TRAIL in UPA-depleted cells arises - in part - from the reduced interaction of the antiapoptotic DcR2 with DISC components.

\section{Discussion}

Despite the conceptually attractive therapeutic features of the TRAIL signaling pathway - such as its unique tumor 
selectivity - only few cases of stable disease and partial remission were observed in clinical trials, suggesting that human tumors are largely resistant to TRAIL-based monotherapies. ${ }^{49}$ These disappointing results were rather unexpected, given the well-documented tumoricidal effects of TRAIL in vitro and the cancer-protective activities of the TRAIL cascade in mouse knockout studies. Indeed, the TRAIL pathway is a natural component of the tumorsurveillance system in mammals that was shown to modulate a

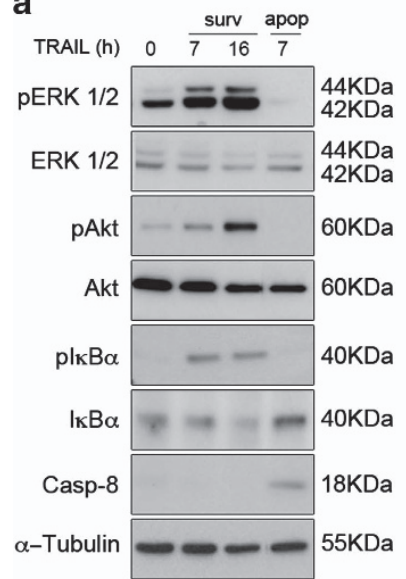

C

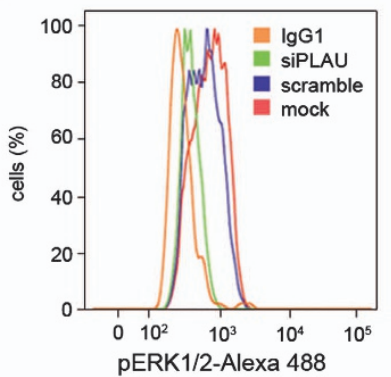

d
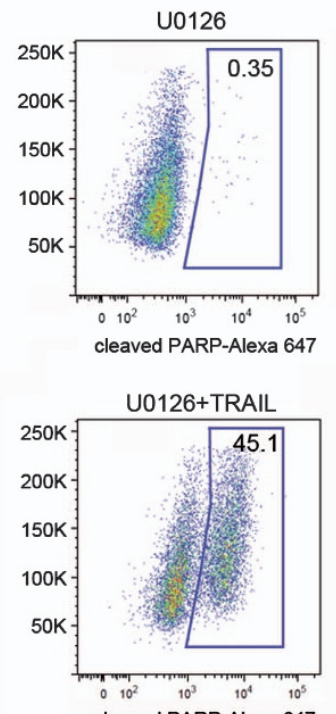

b

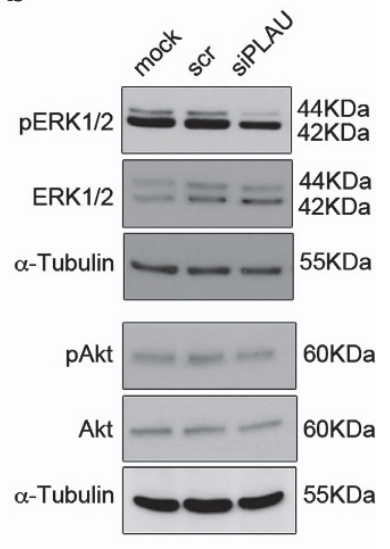

tumor onset/progression and to participate in T-cell-mediated immune defense against tumors in allogenic graft-versustumor settings. ${ }^{16}$ Facing TRAIL challenge, cancer cells may need to develop strategies to survive and proliferate in vivo by acquiring resistance to this cytokine at early steps of the neoplastic transformation. Indeed, activation of survival cascades supporting evasion from apoptosis is one of the hallmarks of cancer. ${ }^{27}$ In that regard, acquisition of resistance to TRAIL-induced cell death during neoplastic transformation may be based on two general mechanistic principles: ${ }^{23}$ (i) key components of the TRAIL pathway may be silenced (e.g., epigenetically) and/or mutated, resulting in a non- or subfunctional signaling cascade and (ii) cancer cells may hijack a functional TRAIL-apoptotic pathway in vivo through the activation of survival cascades that counterbalance TRAIL-induced cell death. In such a scenario, cancer cells would 'hit two birds with one stone' by simultaneously evading from the apoptotic TRAIL challenge imposed by immune surveillance and gaining survival advantage through shifting the TRAIL response from apoptosis to survival/migration. It is therefore of major importance to identify tumor-related features of those cancer cells that have maintained a functional TRAIL-apoptotic pathway and to assess the relative impact of the associated apoptogenic and survival/proliferative functions of this cascade. By following such an approach, we identified PLAU mRNA as a molecule whose high expression is characteristic of cancer cells with a functional TRAIL-apoptotic cascade and whose level has a direct correlation with the sensitivity of cancer cells to trigger TRAIL-induced apoptosis. Surprisingly, we faced an apparent conundrum, as depletion of UPA in these apoptosis-responsive cells enhanced cell death upon cytokine challenge. In that regard, we observed that TRAIL-sensitive cells expressing high levels of PLAU mRNA triggered fractional killing upon TRAIL challenge and survivor cells displayed increased prosurvival signaling. Thus, that UPA and UPAR depletion

Figure 4 uPA knockdown affects ERK1/2 survival signaling. (a) Phosphorylation levels of ERK1/2, Akt and regulators of NF- $\kappa$ B signaling $\left(I_{\kappa} \mathrm{B} \alpha\right)$ in transformed cells surviving TRAIL treatment. BJELR cells were either left untreated ('control') or treated with TRAIL $(1 \mu \mathrm{g} / \mathrm{ml})$ during 7 or $16 \mathrm{~h}$. Apoptotic cells ('apop') were collected by successive washes and non-apoptotic attached cells ('surv') were harvested for western blot analysis. Total and phosphorylated levels of ERK1/2 (Thr202/Tyr204), Akt (Ser 473) and I $\kappa B \alpha($ Ser32/36) were analyzed. Caspase-8 cleavage ('Casp-8') was evaluated in each cell population. $\alpha$-Tubulin, loading control. (b) Phosphorylation status of ERK1/2 and Akt upon UPA knockdown. BJELR cells were left nontransfected ('mock') or transfected either with pooled siRNAs targeting PLAU mRNA ('siPLAU') or non-targeting scramble siRNAs ('scr'). Forty-eight hours after transfection, total and phosphorylated protein levels of ERK1/2 (Thr202/Tyr204) and Akt (Ser 473) were analyzed by western blot analysis. $\alpha$-Tubulin, loading control. (c) Distribution of total (ERK1/2 Alexa488) and phosphorylated ERK1/2 (pERK1/2-Alexa 488; Thr202/Tyr204) in populations of BJELR cells untreated ('mock'), scramble transfected ('scr') and UPA depleted ('siPLAU') was analyzed by flow cytometry. Images represent the distribution of fluorescence within each sample for a representative experiment out of three independent replicates. Isotypic $\lg \mathrm{G} 1$ ('IgG1') was used as control for background florescence. (d) Requirement of ERK1/2 signaling for cell survival upon TRAIL challenge. BJELR cells were either treated for $1 \mathrm{~h}$ with $20 \mu \mathrm{M}$ U0126 MEK $1 / 2$ inhibitor or vehicle (DMSO). Apoptosis in untreated samples ('U0126', 'DMSO') and upon $3 \mathrm{~h}$ of treatment with $1 \mu \mathrm{g} / \mathrm{ml}$ of TRAIL ('U0126 + TRAIL', 'DMSO + TRAIL') was analyzed by flow cytometry as the percentage of cells with positive labeling for cleaved PARP. Images correspond to one representative experiment out of four independent replicates. Percentage of cleaved PARP-positive cells is indicated in the upper right quadrant 
resulted in diminished survival upon challenge with TRAIL highlighted a functional involvement of this cascade in evasion from TRAIL-induced apoptosis. Particularly, we demonstrate that uPA knockdown shifts the profile of Bcl-2 family members to proapoptotic, decreases basal prosurvival ERK1/2 signaling and results in abnormal recruitment of DcR2 to the DISC. The regulation of ERK $1 / 2$ phosphorylation by the UPA/UPAR system can involve the interaction between UPAR and integrins, UPAR and epidermal growth factor (EGF) receptor, as well as cell signaling triggered by soluble UPAR $^{50}$ In these scenarios, uPAR has a central role in modulating the ERK1/2 cascade. In our experiments, sensitization to TRAIL-induced cell death was also observed upon uPAR knockdown, but surprisingly, no major differences in ERK1/2 phosphorylation were seen (data not shown). This suggests the existence of a uPAR-independent/uPA-dependent modulation of ERK1/2
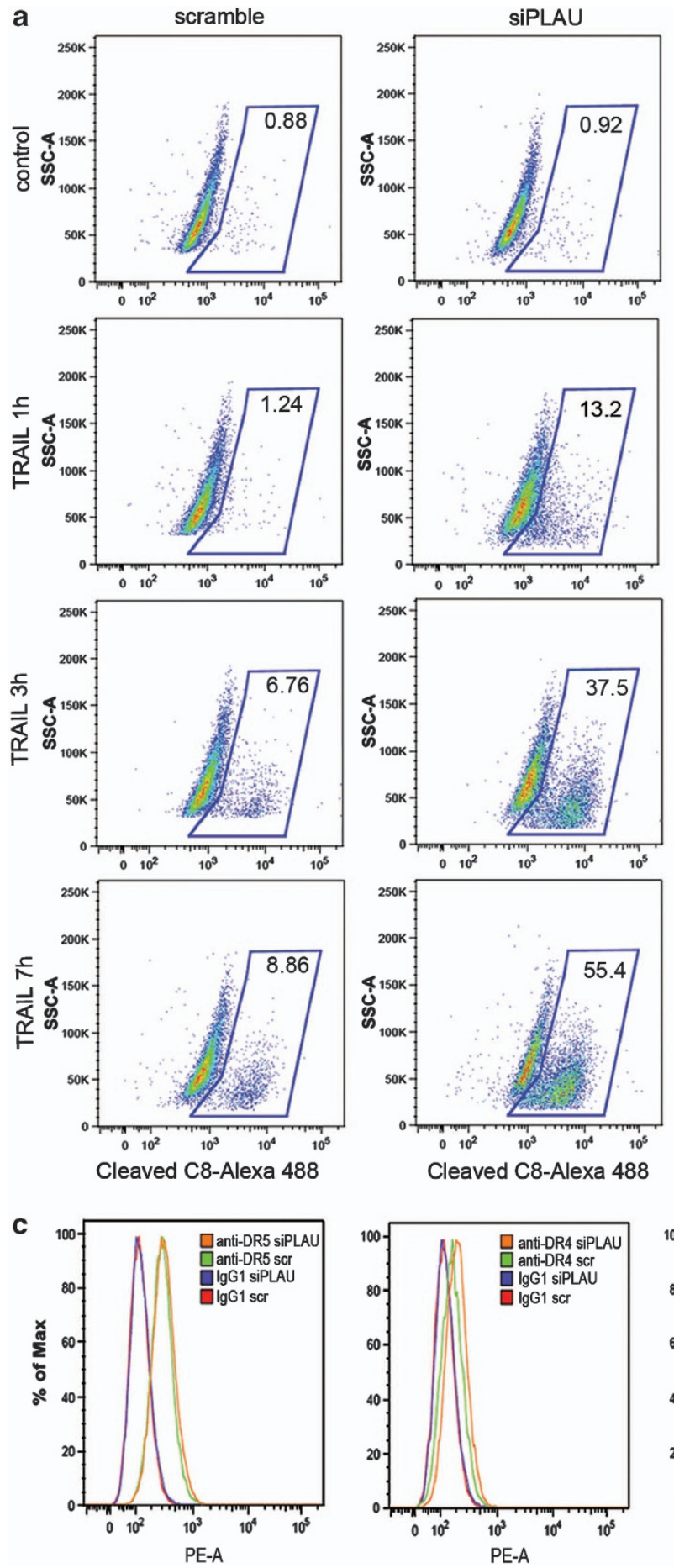

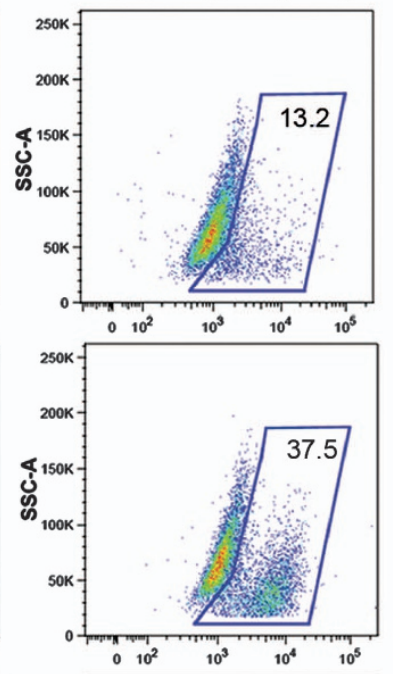

b
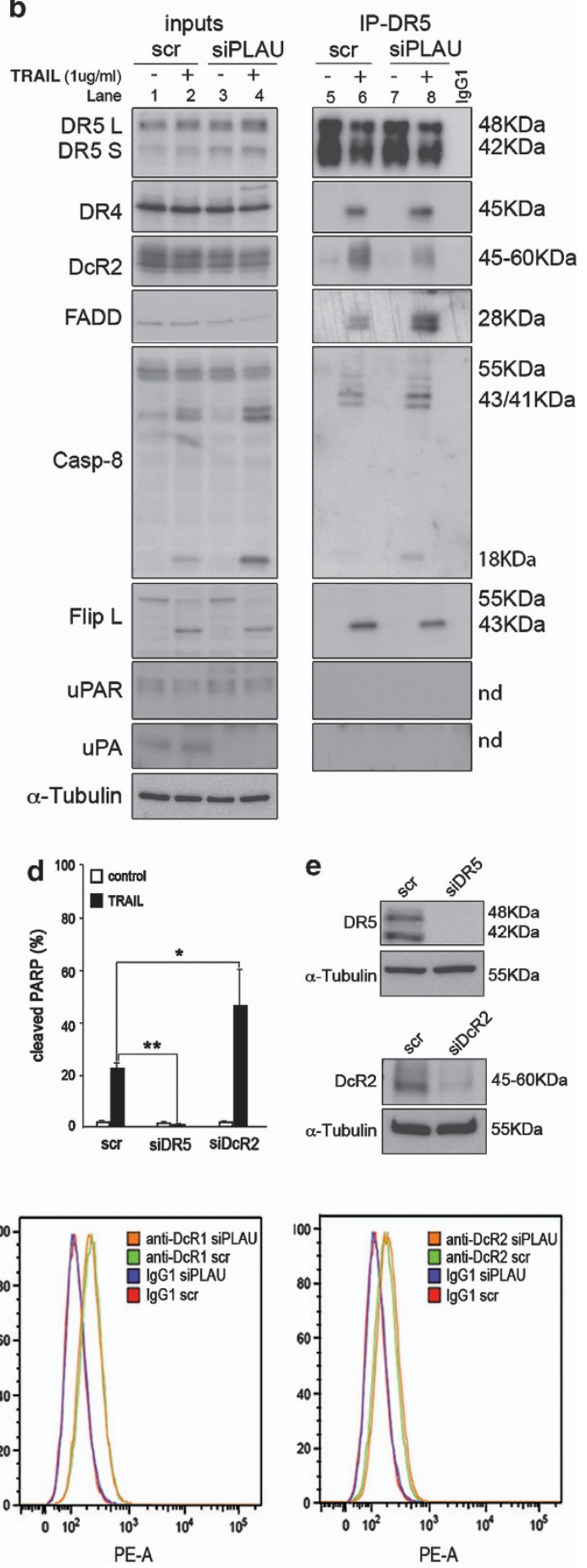
signaling in this experimental model. Supporting this hypothesis, UPAR-independent UPA signaling has been ascribed its binding to other receptors (e.g., $\alpha \mathrm{M} \beta 2$-, $\alpha 5 \beta 5$-integrin) and/ or to its UPAR-independent proteolytic activity. ${ }^{51,52}$

That depletion of UPA alters the DISC composition by reducing the recruitment of antiapoptotic DcR2 suggests a cross-talk between uPA signaling and the formation of TRAIL receptor complexes. Importantly, regulation of signaling from plasma membrane-bound receptors by uPA/uPAR has been reported. Indeed, it has been shown that binding of UPAR to integrins, FPRL1 and EGF receptors subverts the liganddependent signaling toward the formation of new signaling complexes. ${ }^{50}$ Interestingly, neither uPAR nor uPA were found to interact with the DISC in our experimental conditions, suggesting that the modulation of DISC composition/processing in response to TRAIL does not rely on a direct interaction between these molecules and TRAIL receptors.

Finally, several factors have been described to correlate with sensitivity or resistance to TRAIL-induced cell death in tumor cells. For example, the expression of GALNT14 correlates with sensitivity to TRAIL-induced apoptosis in human cancer cell lines and its predictive value is currently tested in phase II clinical trials. ${ }^{53}$ Expression of the homeoprotein Six1 was shown to correlate with resistance to TRAIL-induced cell death and its depletion sensitized cancer cells to apoptosis by this cytokine. ${ }^{54}$ In this context, we show that high PLAU mRNA levels correlate with TRAIL responsiveness and demonstrate that depletion of UPA promotes the apoptogenic action of TRAIL decreasing the risk of generating resistant cells that may turn TRAIL signaling from apoptosis to proliferation/survival. Therefore, uPA/uPAR adds another facet to the TRAIL signaling, which may be considered in therapeutic settings, also in view that TRAILapoptotic action is independent of $p 53 .{ }^{1}$ In that regard, we have shown that high levels of PLAU mRNA are observed in breast tumors showing Her2 +, PgR - and/or p53 mutant phenotypes and that such levels correlate with the apoptotic response of breast cancer cells to TRAIL, suggesting that this type of cancer may express a functional TRAIL cascade. Importantly, first-in-man studies modulating uPA activity ${ }^{55}$ and testing TRAIL-based therapeutics ${ }^{1,49}$ are ongoing. Thus, combinatorial therapies may be envisaged for patients bearing tumors with high PLAU expression and p53 mutations, which are expected to have a poor response to standard treatments. ${ }^{34-36}$

\section{Materials and Methods}

Antibodies. Antibodies for western blotting recognizing the indicated proteins were purchased from Cell Signaling (Beverly, MA, USA; caspase-8 1 C12 no. 9746, cleaved caspase-3 D175 no. 9661, caspase-9 no. 9502 and PARP no. 9542, DR5 no. 3696, DcR2 no. 8049, DcR1 no. 4756, BID no. 2002, Bcl-2 no. 2872, Bcl-xl no. 2762, PTEN no. 9552, PUMA no. 4976, Bak no. 6947, Bim no. 2933, Bax no. 5023, Bad no. 9239, Mcl1 no. 4572, XIAP no. 2045, survivin no. 2808, IAP1 no. 4952, IAP2 no. 3130 , ERK1/2 no. 9102 , pERK1/2 no. 9101 , Akt no. 9272, pAkt no. 9271, $\left.\right|_{\kappa} \mathrm{B} \alpha$ no. 4814, pl $\kappa \mathrm{B} \alpha$ no. 9246), Santa Cruz Biotechnology (Santa Cruz, CA, USA; $\beta$-actin clone sc-1615, $\alpha$-tubulin sc-32293, uPA sc-14019), Millipore EMD Millipore Corporation (Billerica, MA, USA; DR4 AB16955), Alexis Biochemicals, Enzo Life Sciences (Farmingdale, NY, USA), (cFlip ALX-804-428-c050), BD Transduction Laboratories (San Jose, CA, USA; FADD 610399) and Abcam (Cambridge, UK; uPAR ab3129). For flow cytometry assays, APO2.7-PE was purchased from Beckman Coulter (Fullerton, CA, USA; IM2088U), cleaved PARP (no. 8978; no. 6987) and cleaved caspase-8 (no. 9496) from Cell Signaling. DISC immunoprecipitation assays used anti-DR5 (AF631) purchased from R\&D Systems (Minneapolis, MN, USA).

Cell Lines. Cells from stepwise tumorigenesis systems were cultured in DMEM (1 g/l glucose) + Med $199(4: 1)+10 \%$ FCS heat-inactivated (BJ-derived model) and DMEM ( $1 \mathrm{~g} / \mathrm{l}$ glucose) $+10 \%$ FCS heat-inactivated (HEK-derived model). Culture medium was supplemented with $400 \mu \mathrm{g} / \mathrm{ml}$ hygromycin (hTERT selection), $400 \mu \mathrm{g} / \mathrm{ml}$ G418 (SV40 ER selection) and $1 \mu \mathrm{g} / \mathrm{ml}$ puromycin (H-rasV12 selection) when required. Expression of SV40 ER and $H$-rasV12 was confirmed by western blot. LNCaP, PC-3, DU-145, MDA-231, MCF-7, BT-474, 22Rv1 and SKBR3 were obtained from American Type Culture Collection (ATCC, Manassas, VA, USA), and JIMT-1 was purchased from Deutsche Sammlung von Mikroorganismen und Zellkultutren (DSMZ, GmbH, Germany) and grown in recommended media. LAPC4 cells (a kind gift from Prof. C Sawyer, Los Angeles, CA, USA) were grown in Iscove's medium supplemented with $7.5 \%$ FBS supplemented with $2 \mathrm{mM}$ L-glutamine, 1\% penicillin/streptomycin and $10 \mathrm{nM} \mathrm{R} 1881$. VCaP and PC-3MPro4 cells were received from Adrie van Bokhoven (University Medical Center Nijmegen, Nijmegen, The Netherlands) and Marco Ceccini (University of Bern, Bern, Switzerland), respectively, and cultured in RPMI-1640 supplemented with $10 \%$ FBS, $2 \mathrm{mM} \mathrm{L-glutamine}$ and $1 \%$ penicillin/streptomycin.

Microarrays analysis for stepwise tumorigenesis models. Illumina arrays were normalized by quantiles method in R using lummi package. ${ }^{56}$ Analyses were performed using BRB-ArrayTools developed by Dr. Richard Simon and BRB-ArrayTools Development Team. Briefly, univariate t-tests were performed for the different class comparisons (BJ versus BJELR, BJEL versus BJELR, HEK versus HA1ER, HA1E versus HA1ER). The differential expressed genes with a $P$-value $<0.01$, false discovery rate $<0.01$ and fold change $(F C)$ $>2.5$ were selected. Multiple probe i.d.'s were discarded and gene list containing unique names was composed. Hierarchical clustering (complete linkage) and heatmaps were performed using Cluster 3.0 (http://bonsai.hgc.jp/ mdehoon/ software/cluster/software.htm) and Java TreeView, ${ }^{57}$ respectively.

In silico analysis of PLAU mRNA expression. In silico data mining for gene expression levels of PLAU mRNA in clinical samples was carried out using the in silico transcriptomics database (IST) developed at VTT Technical Research Center in Finland. The database covers 113 million data points and is available from the GeneSapiens website (http://www.genesapiens.org). ${ }^{58}$

Figure 5 Altered recruitment of inhibitory components to the DISC promotes caspase-8 activation in uPA knockdown cells. (a) Time-course analysis of procaspase-8 cleavage. BJELR cells were transfected either with pooled siRNAs targeting PLAU mRNA ('siPLAU') or non-targeting scramble siRNAs ('scramble'). Forty-eight hours after transfection, cell populations were either left untreated or challenged with $1 \mu \mathrm{g} / \mathrm{ml}$ TRAIL during 1,3 or $7 \mathrm{~h}$ and the percentage of cells displaying cleaved caspase-8 ('C8') was determined by flow cytometry. Images from one representative experiment out of three independent replicates are shown. Percentage of cleaved C8-positive cells is indicated. (b) DISC composition in uPA-depleted cells. BJELR cells were transfected either with pooled siRNAs targeting PLAU mRNA ('siPLAU') or non-targeting scramble siRNAs ('scr'), and $48 \mathrm{~h}$ after transfection, cell populations were either left untreated or challenged with TRAIL $(1 \mu \mathrm{g} / \mathrm{ml})$ during 30 min. Immunoprecipitation of Death Receptor 5 (IP-DR5) was performed and co-immunoprecipitation of cognate DISC components, UPA and UPAR, was analyzed by western blot analysis. Immunoprecipitation using isotypic IgG1 ('IgG1') was used as background control. (c) Surface levels of TRAIL-Rs upon uPA knockdown. BJELR cells transfected either with pooled siRNAs targeting PLAU mRNA ('siPLAU') or non-targeting scramble siRNAs ('scr'). Forty-eight hours after transfection, surface levels of Death Receptor 5 ('DR5'), Death Receptor 4 ('DR4'), Decoy Receptor 1 ('DcR1') and Decoy Receptor 2 ('DcR2') were analyzed by flow cytometry. Isotypic lgG1 labeling was used as control for background fluorescence in scramble- ('IgG1 scr') and siPLAU- ('IgG1 siPLAU') transfected cells. (d) Antiapoptotic role of DcR2. BJELR cells were transfected either with pooled siRNA targeting Death Receptor 5 mRNA ('siDR5'), Decoy Receptor 2 mRNA ('siDcR2') or non-targeting scramble siRNAs ('scr'), and 48 h after transfection, cell populations were either left untreated or challenged with TRAIL $(1 \mu \mathrm{g} / \mathrm{ml})$ during $3 \mathrm{~h}$. Apoptosis was determined as the percentage of cells with positive labeling for cleaved PARP by flow cytometry. Histograms represent the mean \pm S.D. of three independent biological replicates. Statistical significance was calculated by applying two-tailed, unpaired Student's $t$-test, ${ }^{*} P$-value $<0.05$; ** $P$-value $<0.005$. (e) Efficiency of DR5 and DcR2 knockdown at $48 \mathrm{~h}$ after transfection analyzed by western blot analysis. $\alpha$-Tubulin, loading control 
To determine the expression of PLAU mRNA in 14 different cancer cell lines, we utilized the profiling data from the following resources, which have all been generated using Affymetrix GeneChip U133 Plus 2.0 arrays: (1) GlaxoSmithKline from the National Cancer Institute's cancer Bioinformatics Grid (caBIG). This data set included genome profiling data for over 300 cancer cell lines, available through the caArray open source microarray data management system (https:// cabig.nci.nih.gov/tools/caArray). (2) VTT in-house cell line gene expression profiling database ${ }^{58}$ included data from four breast cancer (JIMT-1, SKBR3, MCF7, BT474) and six prostate cancer (DU-145, PC3, VCAP, LNCaP, LAPC-4 and 22RV1) cell lines. (3) Gene Expression Omnibus (GEO) database. Breast cancer expression set includes breast normal and breast cancer samples from 483 records with GEO series i.d.'s GSE6532, GSE9195, GSE12276, GSE12276 and GSE19615. Only samples with survival information attached were used from the series. From these samples, 79 are annotated as Her2(-) and 36 as Her2 $(+)$. Probes were summarized according to improved probe definitions (custom CDF hgu133plus2hsensgcdf, version 12$)^{59}$ and data were normalized using the robust multiarray (RMA) average expression measure with R/Bioconductor v.2.9.1. Kaplan-Meier plots were drawn using $\mathrm{R}$ standard functions. $P$-values for survival were calculated with $\chi^{2}$ statistics of the rank sum. For between-group comparisons at the gene level two-tailed Student's $t$-test was used.

Transfection. Smart pool siRNAs targeting DR5 mRNA (L-004448-00), DR4 mRNA (L-008090-00), DcR2 mRNA (L-008092-01), cFLIP mRNA (L-003772-00), PLAU mRNA (L-006000-00), PLAUR mRNA (L-0063388-00), Bid mRNA (L-004387-00-0005), Bak (J-003305-07) and non-targeting scrambled no. 1 (D-001810-10-05), as well as single siRNAs targeting different regions of PLAU mRNA (LU-006000-00) were purchased from Dharmacon, Thermo Scientific (Waltham, MA, USA). siRNA targeting Bim (no. 6518) was purchased from Cell Signaling. These siRNAs were transfected into BJELR and/or HA1ER cells by using RNAi Max Lipofectamine following the vendor's intructions (Invitrogen, Life Technologies, Carlsbad, CA, USA). Twenty-four hours after transfection, the culture medium was replaced and cells were incubated under normal growth conditions $\left(37^{\circ} \mathrm{C}, 5 \% \mathrm{CO}_{2}\right)$ for additional $24 \mathrm{~h}$.

Apoptosis measurement. Apoptosis was determined either as the percentage of cells displaying sub-G1 DNA content or a positive immunostaining for the APO 2.7 mitochondrial marker, cleaved PARP or cleaved caspase-8 following the manufacturer's instructions. Apoptotic rate in non-treated control cells and upon TRAIL challenge is displayed as the percentage of cells presenting a positive staining for the indicated marker. When displayed as histograms, each data set was derived from at least two independent biological replicates.

Analysis of growth inhibition upon TRAIL. Cell viability following exposure to TRAIL in 11 different cancer cell lines (LNCaP, PC-3, DU-145, MDA-231, MCF-7, BT-474, 22Rv1, SKBR3, VCap and LAPC) was determined by CellTiter-Glo Luminescence Assay following the manufacturer's instructions (Promega, Madison, WI, USA). Briefly, cells were plated in 384 -well plates, and $24 \mathrm{~h}$ after plating, cells were treated with $400 \mathrm{ng} / \mathrm{ml}$ of TRAlL for $48 \mathrm{~h}$ and cell viability was measured. The percentage of cell viability was determined as: luminescence value in TRAIL-treated cells/luminescence value in non-treated controls. Percentage of cell death displayed in Figure $2 \mathrm{~d}$ was calculated as: $100 \%$ - $\%$ of cell viability.

Growth curve assays. HA1ER and BJELR cells were plated in 48-well plates, and after $20 \mathrm{~h}$, a first dose of TRAlL (100 or $400 \mathrm{ng} / \mathrm{ml}$ ) was added to the medium. A second, a third and a fourth dose were administered 16, 40 and $64 \mathrm{~h}$ after the first treatment. Growth curves were obtained using Incucyte (Essen Instruments, Ann Arbor, MI, USA) under normal culture conditions. Phase-contrast images of cells were taken every hour during 4 days and temporal plots of confluence were established to analyze cell growth. Results are shown as the mean of two technical replicates and are representative of three independent biological repeats.

Western blot assays. Samples were harvested in RIPA buffer, separated by SDS-PAGE and electrotransferred onto nitrocellulose membranes. Membranes were blocked with $5 \%$ non-fat dry milk and $0.1 \%$ Tween-20 in PBS for $1 \mathrm{~h}$ at room temperature and incubated overnight at $4{ }^{\circ} \mathrm{C}$ with primary antibodies according to the manufacturer's instructions, followed by incubation with corresponding secondary peroxidase-conjugated antibodies. $\beta$-Actin or $\alpha$-tubulin was used as an internal standard for protein loading. Immunoreactive bands were visualized by enhanced chemiluminescence and subsequent exposure to hyperfilm (Amersham, GE Healthcare, Amersham, UK). Images were scanned and processed by Adobe
Photoshop CS2 software (San Jose, CA, USA). Images from one representative experiment out of at least two biological replicates are displayed.

Surface levels of TRAIL receptors. Antibodies were purchased from Diaclone Immunology Products (Diaclone, Besancon, France; TRAIL R1 854.852.010; TRAIL R2 854.862.010; TRAIL R3 854.892.010 and TRAIL R4 854.972.010) and detection was performed following the manufacturer's instructions. ${ }^{60}$

DISC immunoprecipitation. BJELR cells were plated in a confluency of $10^{6}$ cells per $10 \mathrm{~cm}$ Petri dishes. Twenty-four hours later, cells were exposed to TRAIL $1 \mu \mathrm{g} / \mathrm{ml}$ ) during $30 \mathrm{~min}$ at regular growing conditions $\left(37^{\circ} \mathrm{C} ; 5 \% \mathrm{CO}_{2}\right)$. Cells were washed with ice-cold PBS and lysed in $1 \mathrm{ml}$ of lysis buffer $(30 \mathrm{mM}$ Tris- $\mathrm{HCl}$ (pH 7.4), $150 \mathrm{mM} \mathrm{NaCl}, 5 \mathrm{mM} \mathrm{KCl}, 10 \%$ glycerol, $2 \mathrm{mM}$ EDTA (pH 8.0)) freshly supplemented with complete, EDTA-free protease inhibitor cocktail (Roche, Mannheim Germany; no. 11873580001), phosphatase inhibitors (PhosStop; Roche) and 1\% Triton X-100 (Bio-Rad). Lysates were precleared with Pure Proteome Protein G magnetic beads (Millipore; LSKMAGG02) and the DISC was immunoprecipitated by using $10 \mu \mathrm{g}$ of anti-DR5 antibody bound to Pure Proteome Protein G magnetic beads (Millipore; LSKMAGG02). Immunoprecipitates were processed for immunoblotting as described in western blot section.

\section{Conflict of Interest}

The authors declare no conflict of interest.

Acknowledgements. Stepwise tumorigenesis systems were kindly provided by William C Hahn (Dana-Farber Cancer Institute). Transcriptome analyses were performed using BRB-ArrayTools developed by Dr. Richard Simon and BRBArrayTools Development Team. We thank the European Commission (LSHC-CT2005-518417 'Epitron', HEALTH-F4-2007-200767 'Apo-Sys'H Gronemeyer and $\mathrm{O}$ Kallioniemi laboratories), the Ligue Contre le Cancer (H Gronemeyer, equipe labellisée), the Association pour la recherche sur le cancer (ARC), the Agence Nationale de la Recherche (ANR) and the Institut National du Cancer (INCa) for financial support. We thank Irene Yujnovsky and Maximiliano Portal for helpful discussions and critical reading of the manuscript and Dorothée Jean for technical assistance. Yelyzaveta Shlyakhtina is a recipient of a Doctoral Fellowship from the IGBMC International PhD Program, Danilo G Ceschin was a recipient of a Postdoctoral fellowship from Foundation pour la Recherche Medicale and Valeria Pavet was a recipient of a Senior Postdoctoral fellowship from the Ligue Contre le Cancer.

1. Ashkenazi A, Holland P, Eckhardt SG. Ligand-based targeting of apoptosis in cancer: the potential of recombinant human apoptosis ligand 2/tumor necrosis factor-related apoptosis-inducing ligand (rhApo2L/TRAIL). J Clin Oncol 2008; 26: 3621-3630.

2. Pan G, O'Rourke K, Chinnaiyan AM, Gentz R, Ebner R, Ni J et al. The receptor for the cytotoxic ligand TRAIL. Science 1997; 276: 111-113.

3. Screaton GR, Mongkolsapaya J, Xu XN, Cowper AE, McMichael AJ, Bell JI. TRICK2, a new alternatively spliced receptor that transduces the cytotoxic signal from TRAIL. Curr Biol 1997; 7: 693-696.

4. Walczak H, Degli-Esposti MA, Johnson RS, Smolak PJ, Waugh JY, Boiani N et al. TRAIL-R2: a novel apoptosis-mediating receptor for TRAIL. EMBO J 1997; 16: 5386-5397.

5. MacFarlane M, Ahmad M, Srinivasula SM, Fernandes-Alnemri T, Cohen GM, Alnemri ES Identification and molecular cloning of two novel receptors for the cytotoxic ligand TRAIL. J Biol Chem 1997; 272: 25417-25420.

6. Oberst A, Pop C, Tremblay AG, Blais V, Denault JB, Salvesen GS et al. Inducible dimerization and inducible cleavage reveal a requirement for both processes in caspase-8 activation. J Biol Chem 2010; 285: 16632-16642.

7. Pitti RM, Marsters SA, Ruppert S, Donahue CJ, Moore A, Ashkenazi A. Induction of apoptosis by Apo-2 ligand, a new member of the tumor necrosis factor cytokine family. J Biol Chem 1996; 271: 12687-12690.

8. Zhang L, Fang B. Mechanisms of resistance to TRAIL-induced apoptosis in cancer. Cancer Gene Ther 2005; 12: 228-237.

9. Lalaoui N, Morle A, Merino D, Jacquemin G, lessi E, Morizot A et al. TRAIL-R4 promotes tumor growth and resistance to apoptosis in cervical carcinoma HeLa cells through AKT. PLoS One 2011; 6: e19679.

10. Sheridan JP, Marsters SA, Pitti RM, Gumey A, Skubatch M, Baldwin D et al. Control of TRAILinduced apoptosis by a family of signaling and decoy receptors. Science 1997; 277: 818-821.

11. Pan G, Ni J, Wei YF, Yu G, Gentz R, Dixit VM. An antagonist decoy receptor and a death domain-containing receptor for TRAIL. Science 1997; 277: 815-818.

12. Kataoka T, Schroter M, Hahne M, Schneider P, Irmler M, Thome M et al. FLIP prevents apoptosis induced by death receptors but not by perforin/granzyme $B$, chemotherapeutic drugs, and gamma irradiation. J Immunol 1998; 161: 3936-3942. 
13. Inohara N, Koseki T, Hu Y, Chen S, Nunez G. CLARP, a death effector domain-containing protein interacts with caspase-8 and regulates apoptosis. Proc Natl Acad Sci USA 1997; 94: 10717-10722.

14. Goltsev YV, Kovalenko AV, Arnold E, Varfolomeev EE, Brodianskii VM, Wallach D. CASH, a novel caspase homologue with death effector domains. J Biol Chem 1997; 272: 19641-19644.

15. Fulda S, Meyer E, Debatin KM. Inhibition of TRAlL-induced apoptosis by Bcl-2 overexpression. Oncogene 2002; 21: 2283-2294.

16. Johnstone RW, Frew AJ, Smyth MJ. The TRAIL apoptotic pathway in cancer onset, progression and therapy. Nat Rev Cancer 2008; 8: 782-798.

17. Azijli K, Weyhenmeyer B, Peters GJ, de Jong S, Kruyt FA. Non-canonical kinase signaling by the death ligand TRAIL in cancer cells: discord in the death receptor family. Cell Death Differ 2013; 20: 858-868.

18. Ehrhardt H, Fulda S, Schmid I, Hiscott J, Debatin KM, Jeremias I. TRAIL induced surviva and proliferation in cancer cells resistant towards TRAIL-induced apoptosis mediated by NF-kappaB. Oncogene 2003; 22: 3842-3852.

19. Flusberg DA, Roux J, Spencer SL, Sorger PK. Cells surviving fractional killing by TRAIL exhibit transient but sustainable resistance and inflammatory phenotypes. Mol Biol Cell 2013; 24: 2186-2200.

20. Degli-Esposti MA, Dougall WC, Smolak PJ, Waugh JY, Smith CA, Goodwin RG. The novel receptor TRAIL-R4 induces NF-kappaB and protects against TRAIL-mediated apoptosis, yet retains an incomplete death domain. Immunity 1997; 7: 813-820.

21. Spencer SL, Gaudet S, Albeck JG, Burke JM, Sorger PK. Non-genetic origins of cell-to-cell variability in TRAIL-induced apoptosis. Nature 2009; 459: 428-432.

22. Varfolomeev E, Maecker H, Sharp D, Lawrence D, Renz M, Vucic D et al. Molecular determinants of kinase pathway activation by Apo2 ligand/tumor necrosis factor-related apoptosis-inducing ligand. J Biol Chem 2005; 280: 40599-40608.

23. Dimberg LY, Anderson CK, Camidge R, Behbakht K, Thorburn A, Ford HL. On the TRAIL to successful cancer therapy? Predicting and counteracting resistance against TRAIL-based therapeutics. Oncogene 2012; 32: 1341-1350.

24. Menke C, Bin L, Thorburn J, Behbakht K, Ford HL, Thorburn A. Distinct TRAIL resistance mechanisms can be overcome by proteasome inhibition but not generally by synergizing agents. Cancer Res 2011; 71: 1883-1892.

25. Hahn WC, Counter CM, Lundberg AS, Beijersbergen RL, Brooks MW, Weinberg RA Creation of human tumour cells with defined genetic elements. Nature 1999; 400: 464-468

26. Elenbaas B, Spirio L, Koerner F, Fleming MD, Zimonjic DB, Donaher JL et al. Human breast cancer cells generated by oncogenic transformation of primary mammary epithelial cells. Genes Dev 2001; 15: 50-65

27. Hanahan D, Weinberg RA. Hallmarks of cancer: the next generation. Cell 2011; 144 646-674.

28. Pavet V, Beyrath J, Pardin C, Morizot A, Lechner MC, Briand JP et al. Multivalent DR5 peptides activate the TRAIL death pathway and exert tumoricidal activity. Cancer Res 2010; 70: 1101-1110.

29. Lund P, Kotova I, Kedinger V, Khanwalkar H, Voltz E, Hahn WC et al. Transformation-dependent silencing of tumor-selective apoptosis-inducing TRAIL by DNA hypermethylation is antagonized by decitabine. Mol Cancer Ther 2011; 10: 1611-1623.

30. Wang Y, Engels IH, Knee DA, Nasoff M, Deveraux QL, Quon KC. Synthetic lethal targeting of MYC by activation of the DR5 death receptor pathway. Cancer Cell 2004; 5: 501-512.

31. Nesterov A, Nikrad M, Johnson T, Kraft AS. Oncogenic Ras sensitizes normal human cells to tumor necrosis factor-alpha-related apoptosis-inducing ligand-induced apoptosis. Cancer Res 2004; 64: 3922-3927.

32. Duffy MJ, Duggan C, Mulcahy HE, McDermott EW, O'Higgins NJ. Urokinase plasminogen activator: a prognostic marker in breast cancer including patients with axillary nodenegative disease. Clin Chem 1998; 44(Part 1): 1177-1183.

33. Look MP, van Putten WL, Duffy MJ, Harbeck N, Christensen IJ, Thomssen C et al. Pooled analysis of prognostic impact of urokinase-type plasminogen activator and its inhibitor PAl-1 in 8377 breast cancer patients. J Natl Cancer Inst 2002; 94: 116-128.

34. Janicke F, Prechtl A, Thomssen C, Harbeck N, Meisner C, Untch M et al. Randomized adjuvant chemotherapy trial in high-risk, lymph node-negative breast cancer patients identified by urokinase-type plasminogen activator and plasminogen activator inhibitor type 1 J Natl Cancer Inst 2001; 93: 913-920.

35. Annecke K, Schmitt M, Euler U, Zerm M, Paepke D, Paepke S et al. UPA and PAI-1 in breast cancer: review of their clinical utility and current validation in the prospective NNBC-3 trial. Adv Clin Chem 2008; 45: 31-45.

36. Harbeck N, Kates RE, Schmitt M, Gauger K, Kiechle M, Janicke F et al. Urokinase-type plasminogen activator and its inhibitor type 1 predict disease outcome and therapy response in primary breast cancer. Clin Breast Cancer 2004; 5: 348-352.

37. Rahman M, Davis SR, Pumphrey JG, Bao J, Nau MM, Meltzer PS et al. TRAIL induces apoptosis in triple-negative breast cancer cells with a mesenchymal phenotype. Breast Cancer Res Treat 2009; 113: 217-230.

38. Besch R, Berking C, Kammerbauer C, Degitz K. Inhibition of urokinase-type plasminogen activator receptor induces apoptosis in melanoma cells by activation of p53. Cell Death Differ 2007; 14: 818-829.
39. Gondi CS, Kandhukuri N, Dinh DH, Gujrati M, Rao JS. Down-regulation of UPAR and uPA activates caspase-mediated apoptosis and inhibits the PI3K/AKT pathway. Int $\mathrm{J}$ Oncol 2007; 31: 19-27.

40. Subramanian R, Gondi CS, Lakka SS, Jutla A, Rao JS. siRNA-mediated simultaneous downregulation of UPA and its receptor inhibits angiogenesis and invasiveness triggering apoptosis in breast cancer cells. Int J Oncol 2006; 28: 831-839.

41. Tkachuk N, Kiyan J, Tkachuk S, Kiyan R, Shushakova N, Haller H et al. Urokinase induces survival or pro-apoptotic signals in human mesangial cells depending on the apoptotic stimulus. Biochem J 2008; 415: 265-273.

42. Cao DJ, Guo YL, Colman RW. Urokinase-type plasminogen activator receptor is involved in mediating the apoptotic effect of cleaved high molecular weight kininogen in human endothelial cells. Circ Res 2004; 94: 1227-1234.

43. Zhang X, Chaudhry A, Chintala SK. Inhibition of plasminogen activation protects against ganglion cell loss in a mouse model of retinal damage. Mol Vis 2003; 9: 238-248.

44. Jouan-Lanhouet S, Arshad MI, Piquet-Pellorce C, Martin-Chouly C, Le Moigne-Muller G, Van Herreweghe $F$ et al. TRAIL induces necroptosis involving RIPK1/RIPK3-dependent PARP-1 activation. Cell Death Differ 2012; 19: 2003-2014.

45. Krishnamoorthy B, Darnay B, Aggarwal B, Dinh DH, Kouraklis G, Olivero WC et al. Glioma cells deficient in urokinase plaminogen activator receptor expression are susceptible to tumor necrosis factor-alpha-related apoptosis-inducing ligand-induced apoptosis. Clin Cancer Res 2001; 7: 4195-4201.

46. Nguyen DH, Hussaini IM, Gonias SL. Binding of urokinase-type plasminogen activator to its receptor in MCF-7 cells activates extracellular signal-regulated kinase 1 and 2 which is required for increased cellular motility. J Biol Chem 1998; 273: 8502-8507.

47. Nguyen DH, Webb DJ, Catling AD, Song Q, Dhakephalkar A, Weber MJ et al. Urokinase-type plasminogen activator stimulates the Ras/extracellular signal-regulated kinase (ERK) signaling pathway and MCF-7 cell migration by a mechanism that requires focal adhesion kinase, Src, and Shc. Rapid dissociation of GRB2/Sps-Shc complex is associated with the transient phosphorylation of ERK in urokinase-treated cells. J Biol Chem 2000; 275: 19382-19388.

48. Clancy L, Mruk K, Archer K, Woelfel M, Mongkolsapaya J, Screaton G et al. Preligand assembly domain-mediated ligand-independent association between TRAIL receptor 4 (TR4) and TR2 regulates TRAIL-induced apoptosis. Proc Natl Acad Sci USA 2005; 102: 18099-18104.

49. Pavet V, Portal MM, Moulin JC, Herbrecht R, Gronemeyer H. Towards novel paradigms for cancer therapy. Oncogene 2010; 30: 1-20.

50. Smith HW, Marshall CJ. Regulation of cell signalling by uPAR. Nat Rev Mol Cell Biol 2009; 11: $23-36$

51. Alfano D, Franco P, Vocca I, Gambi N, Pisa V, Mancini A et al. The urokinase plasminogen activator and its receptor: role in cell growth and apoptosis. Thromb Haemost 2005; 93 : 205-211.

52. Konakova M, Hucho F, Schleuning WD. Downstream targets of urokinase-type plasminogen-activator-mediated signal transduction. Eur J Biochem 1998; 253: 421-429.

53. Wagner KW, Punnoose EA, Januario T, Lawrence DA, Pitti RM, Lancaster K et al. Death-receptor O-glycosylation controls tumor-cell sensitivity to the proapoptotic ligand Apo2L/TRAIL. Nat Med 2007; 13: 1070-1077.

54. Behbakht K, Qamar L, Aldridge CS, Coletta RD, Davidson SA, Thorburn A et al. Six 1 overexpression in ovarian carcinoma causes resistance to TRAIL-mediated apoptosis and is associated with poor survival. Cancer Res 2007; 67: 3036-3042.

55. Schmitt M, Harbeck N, Brunner N, Janicke F, Meisner C, Muhlenweg B et al. Cancer therapy trials employing level-of-evidence-1 disease forecast cancer biomarkers uPA and its inhibitor PAl-1. Expert Rev Mol Diagn 2011; 11: 617-634.

56. Du P, Kibbe WA, Lin SM. Lumi: a pipeline for processing Illumina microarray. Bioinformatics 2008; 24: 1547-1548.

57. Saldanha AJ. Java Treeview - extensible visualization of microarray data. Bioinformatics 2004; 20: 3246-3248

58. Kilpinen S, Autio R, Ojala K, lljin K, Bucher E, Sara H et al. Systematic bioinformatic analysis of expression levels of 17,330 human genes across 9,783 samples from 175 types of healthy and pathological tissues. Genome Biol 2008; 9: R139.

59. Dai M, Wang P, Boyd AD, Kostov G, Athey B, Jones EG et al. Evolving gene/transcript definitions significantly alter the interpretation of GeneChip data. Nucleic Acids Res 2005; 33: e175

60. Merino D, Lalaoui N, Morizot A, Schneider P, Solary E, Micheau O. Differential inhibition of TRAIL-mediated DR5-DISC formation by decoy receptors 1 and 2. Mol Cell Biol 2006; 26: 7046-7055.

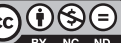

Cell Death and Disease is an open-access journal published by Nature Publishing Group. This work is licensed under a Creative Commons Attribution-NonCommercialNoDerivs 3.0 Unported License. To view a copy of this license, visit http://creativecommons.org/licenses/by-nc-nd/3.0/ 